\title{
Effectiveness of public health programs for decreasing alcohol consumption
}

This article was published in the following Dove Press journal:

Patient Intelligence

12 May 201 I

Number of times this article has been viewed

\author{
Susan Kelly-Weeder \\ Kathryn Phillips \\ Shannon Rounseville \\ William F Connell School \\ of Nursing, Boston College, \\ Chestnut Hill, MA, USA
}

Correspondence: Susan Kelly-Weeder William F Connell School of Nursing, Cushing Hall, Boston College, I 40 Commonwealth Avenue, Chestnut Hill, MA 02467, USA

Tel +l 6175528018

Fax + I 6175520745

Email kellywee@bc.edu
Abstract: Excessive alcohol consumption and the associated negative consequences are a major public health concern in the United States and throughout the world. Historically, there have been numerous attempts to develop policies and prevention programs aimed at decreasing high-risk alcohol use. Policy initiatives have demonstrated considerable effectiveness and include changes in the minimum legal drinking age, reductions in acceptable legal limits for blood alcohol concentration while operating a motor vehicle, as well as decreasing availability and access to alcohol for underage individuals. Primary prevention programs that have used exclusively educational approaches have received mixed results. Increasing effectiveness has been associated with prevention programs that have utilized a multi-component approach and have included educational initiatives with environmental changes.

Keywords: alcohol abuse, underage, public health, programs, binge drinking

\section{Introduction}

Alcohol use is a significant public health problem. In the United States (US) alone, $61.2 \%$ of adults are current drinkers ${ }^{1}$ and according the National Epidemiologic Survey of Alcohol and Related Conditions (NESARC), 8.5\% of American adults have an alcohol use disorder. ${ }^{2}$ The percentages of adolescents and young adults who report high-risk drinking behaviors are of increasing concern. Among adolescents (aged 12-17 years), $21 \%$ are current drinkers and $10 \%$ report heavy or binge drinking, defined as five or more drinks within a 2-hour period. ${ }^{3}$ College students are a particular highrisk group, with greater than $40 \%$ reporting recent binge drinking. ${ }^{4}$ A standard drink in the US contains 13.7 grams ( 0.6 ounces) of pure alcohol and generally is equivalent to a 12 ounce beer, 8 ounces of malt liquor, 5 ounces of wine, or 1.5 ounces of 80-proof distilled liquor (ie, gin, vodka, whiskey). ${ }^{5}$

The highest prevalence of alcohol dependence occurs in adolescents and young adults between the ages of 18 and $25 .{ }^{6}$ The concentration of misuse in this age period is of concern as researchers have suggested that an earlier onset of alcohol dependence leads to a more severe form of alcoholism, reduced treatment efficacy, and greater relapse rates. ${ }^{7}$ The frequency of alcohol use in this age group is also problematic. A recent national survey indicated that $72 \%$ of high school seniors (commonly aged 17-18) reported consuming alcohol in their lifetimes, $43 \%$ had consumed alcohol in the last 30 days, and $25 \%$ reported binge drinking in the last 2 weeks. ${ }^{8}$ The peak period for the onset of alcohol use is between the ages of 10 and 17 , with $30 \%-40 \%$ of adolescents initiating alcohol use before the age of $14 .{ }^{9}$ While drinking rates in younger adolescents 
are similar, a gender differential develops in later adolescence in which males are more likely to be current drinkers and are reported to use greater amounts of alcohol. ${ }^{10}$

Of particular concern is the emerging evidence linking adolescent alcohol use to changes in brain development. Adolescence marks a period of rapid brain growth and remodeling particularly in the prefrontal cortex, which is responsible for cognitive flexibility, self-regulation, and evaluation of risk versus reward. ${ }^{11}$ Additional maturation processes are underway in the hippocampus and limbic systems. ${ }^{12}$ Magnetic resonance imaging studies have suggested that adolescents with alcohol use disorders have reductions in the size of the hippocampus, a part of the brain involved in memory and spatial navigation. ${ }^{13-16}$ Additional studies that have investigated brain remodeling suggest that the overproduction and elimination of synapses in the prefrontal cortex extends through young adulthood and that episodes of heavy drinking could interfere with the attainment of mature cognitive and behavioral functioning. ${ }^{11}$

Medical consequences associated with alcohol misuse are well documented and include the development of chronic illnesses, malignancies, and both intentional and unintentional injuries. ${ }^{17}$ A vast number of social problems including disrupted interpersonal relationships, workplace issues, as well as violent and nonviolent crimes can also be attributed to alcohol use. ${ }^{18}$ However, the most troubling findings are those that link alcohol use to fatalities. Excessive alcohol use is the third leading cause of preventable death in the US ${ }^{19}$ and the fifth leading risk factor for premature death and disability throughout the world. ${ }^{20}$ The most recent college data indicate the rates of unintentional deaths for college students have increased $3 \%$ since $1998 .^{21}$

In light of the far-reaching problems associated with its use, the World Health Organization (WHO) has identified the prevention of harmful alcohol use as a priority. The WHO suggests that strategies to reduce alcohol use should be evidenced-based, address levels, patterns and context of use, and target both the general population as well as vulnerable and affected individuals. ${ }^{22}$ Multiple public health initiatives have been implemented throughout the US. These measures are primarily related to the development of policies regulating alcohol-related behaviors, primary prevention programs focused on increasing public awareness of the risks associated with alcohol use, and federally and state sponsored efforts to expand the scope of medical practice to include screening and intervention for high-risk and dependent drinking known as SBIRT programs. ${ }^{23}$ Therefore, the purpose of this review is to describe the public health interventions that have been implemented to address high-risk alcohol use and to investigate the effectiveness of these initiatives.

In order to identify relevant articles for inclusion, a PubMed search of the relevant literature was conducted. Search terms included alcohol use, public health interventions to reduce alcohol consumption, educational, family and community programming, as well as adolescent and college prevention initiatives. Original research and comprehensive review articles published within the last 5 years were included, as well as seminal works identified through the review of relevant reference lists. All non-English language articles were excluded.

\section{Policy initiatives}

Historically, there have been many attempts to decrease the public's consumption of alcohol. In the mid to late $1800 \mathrm{~s}$, the Protestant church played a dominant role in the development of the American Society for the Promotion of Temperance (APST), an organization that promoted abstinence and punishment for inebriation. ${ }^{24}$ Support for the APST was very strong among women, who developed their own organization, the Women's Christian Temperance Society (WCTS). The focus of the WCTS was educating students regarding the perils of alcohol use, in hopes of changing social norms. ${ }^{25}$

Along with other temperance groups, the APST and the WCTS were instrumental in the passage of the 18th Amendment on January 16, 1919. ${ }^{26}$ The 18 th amendment, also known as "Prohibition", prohibited the sale and distribution of intoxicating alcohol. ${ }^{24}$ Today, historians view Prohibition as a "failed social experiment" because during that time, most Americans ignored the legislation, alcohol problems increased as drinkers switched to hard liquor, and a black market was created which directly contributed to the development of organized crime in the US. ${ }^{26}$ Due to ongoing difficulties in enforcement and decreasing effectiveness, Prohibition was repealed in 1933. While Prohibition was not an effective deterrent, it was the first federal US legislation to address the prevention of alcohol use.

Following Prohibition, nearly every state in the US restricted alcohol access to adults over the age of 21 ; however, in the mid-1970s, many states lowered the drinking age to 18,19 , or $20 .{ }^{27}$ Several studies implemented following these reductions in the legal drinking age indicated a significant increase in motor vehicle accidents, injuries, and fatalities. ${ }^{27}$ Based on these findings, community action groups began pressuring state legislators to repeal the reduced age limits and reinstate 21 as the minimum legal drinking age (MLDA). In 1984 the federal government enacted the Uniform 
Drinking Age Act, which mandated reduced transportation funds to any state that did not raise the MLDA to $21 .{ }^{27} \mathrm{In}$ 1988 , just 4 years after this bill was enacted, all 50 states were in compliance with this legislation. ${ }^{28}$

Increasing the MLDA to 21 has been cited as one of the most important policy actions of the last generation. ${ }^{10}$ While there are some authorities who negate the impact of this legislation, ${ }^{29}$ there is ample evidence to suggest a dramatic improvement in public health due to the reductions in fatal car crashes amongst $18-20$ year olds. ${ }^{10}$ In a recent review, McCartt and associates reported that MLDAs of 21 reduce drinking, problematic drinking, drinking and driving, and alcohol-related crashes in young adults. ${ }^{30}$ Studies have also reported long-term differences in drinking outcomes related to the MLDA legislation. Norberg reported that the benefit of these laws even extended to adults, in that adult participants not exposed to MLDA regulations, were more likely to develop alcohol use disorders than were adults who were governed by MLDA legislation. ${ }^{31}$

Policy regulations related to driving limits based on elevated levels of blood alcohol have been reported to be effective in reducing alcohol-related negative outcomes. ${ }^{32}$ In all 50 states and the District of Columbia, it is illegal to drive with an elevated blood alcohol concentration (BAC). In recent years, the majority of states have reduced the illegal BAC from 0.10 to $0.08 . .^{33}$ Blood alcohol concentration is defined as the amount of alcohol present in 100 milliliters $(\mathrm{mL})$ of blood; for example, a BAC of 0.08 indicates 0.08 grams of alcohol in $100 \mathrm{mLs}$ of blood. ${ }^{34}$ In an early study, Hingson reported that states which had reduced the legal BAC to 0.08 experienced significant reductions in alcohol-related motor vehicle fatalities. ${ }^{35} \mathrm{~A}$ review of studies that investigated the effectiveness of lowering the BAC reported a 5\%-16\% reduction in alcohol car crashes, fatalities, and injuries. ${ }^{36}$ Research has also indicated that reducing BAC to 0.05 would result in even greater reductions in fatalities; as the relative risk of being in a fatal car crash is 4-10 times higher for drivers with BACs between 0.05 and 0.07 , as compared to drivers who have no evidence of alcohol in their bloodstreams. ${ }^{36}$

Zero tolerance laws are directed at young drivers and set the maximum acceptable blood alcohol level at 0.02 or lower for drivers under the age of $21 .{ }^{37}$ These regulations are supported by the National Highway Systems Act and have been in place since 1998. Early studies indicated a 20\% relative reduction in fatal crashes in states that had enacted zero tolerance laws. ${ }^{38,39}$ Studies have consistently reported the positive impact of these policy regulations, as reductions in fatal car crashes have been associated with decreases in blood alcohol levels, ${ }^{32,36}$ increases in minimum legal drinking age, ${ }^{30,32,40}$ and zero tolerance laws. ${ }^{41}$

Evidence suggests that policies that restrict the availability of alcohol are effective in reducing the harms associated with its use. ${ }^{42,43}$ Early studies indicated that increased alcohol prices were associated with reductions in drinking frequency ${ }^{44}$ and vehicular fatalities. ${ }^{45} \mathrm{~A}$ recent meta-analysis reported a significant inverse relationship between alcohol price and consumption levels with reductions in beer $(r=-0.17)$, wine $(r=-0.30)$, spirits $(r=-0.29)$, and total alcohol use $(r=-0.44)$ associated with increased cost. ${ }^{46}$

Additional strategies to reduce accessibility to alcohol include limiting the hours and/or days of alcohol sales. A recent review by Middleton and associates, reported that reducing the number of days that alcoholic beverages were sold, decreased alcohol consumption and alcohol-related negative consequences. ${ }^{47}$ Duailibi et al investigated the relationship between reduced hours of alcohol service in bars and alcohol-related violence in Brazil. ${ }^{48}$ Results indicated that a reduction in the hours that alcohol was sold was positively correlated with a reduction in violent crimes; however, rates of alcohol consumption were not reported. ${ }^{48}$

The role of alcohol outlet density and its correlation to alcohol-related harms have been studied by increasing numbers of researchers. A variety of methodological designs have been used to investigate these associations and have consistently reported a significant positive relationship between greater outlet density and increased alcohol consumption, injury, violence, and crime. ${ }^{49-52}$ A recent longitudinal study that investigated rates of underage drinking reported higher levels of average and excessive drinking in youth living in communities with higher alcohol outlet densities. ${ }^{53}$ However, these results were tempered by findings that indicated youth with access to transportation overcame geographic constraints and were able to seek alcohol and drinking opportunities in other communities. ${ }^{53}$

While multiple policy initiatives have been implemented to deter drinking and driving, recent data suggest alcohol impaired driving remains a significant problem in the US. Shults and associates analyzed data from the 2001-2003 Injury Control and Risk Survey (ICARIS-2), in which 7 million drivers and 10.5 million passengers over the age 18 were queried regarding their recent history of alcoholimpaired driving and riding with an impaired driver. ${ }^{54}$ The results indicated a 50\% increase in reports of impaired driving and riding with an impaired driver from the first ICARIS study in 1994. These findings reinforce the critical need for 
ongoing and sustained efforts to prevent individuals from driving while under the influence of alcohol. ${ }^{55}$

Sobriety checkpoints have demonstrated promise in reducing the incidence of drunk driving. At sobriety checkpoints, law enforcement officers systematically stop drivers to assess their degree of impairment. In the US, the officer must have reason to suspect that the driver may be impaired, while in Australia and many European countries, random stops are allowed. Once stopped at a checkpoint, drivers are administered a breath test to gauge their alcohol levels. ${ }^{32}$ Deterrence theory underlies the use of sobriety checkpoints and the primary goal of these interventions is to reduce driving after drinking by increasing the perceived risk of arrest. ${ }^{32}$ Studies have consistently reported an approximate $20 \%$ reduction in alcohol-related car crashes as a result of sobriety checkpoints and data further suggest that the effectiveness of these interventions does not diminish over time. ${ }^{55}$

Server intervention training programs provide education to servers of alcoholic beverages with the intention of preventing intoxication and subsequent impaired driving by customers. ${ }^{32}$ While several US states and local governments have mandated server training, there are no standards for these programs and they can vary significantly in their content, instructional time, and method of delivery. ${ }^{32}$ Training programs that are intensive, include face-to-face instruction, and are combined with active management support have been reported to be most effective. ${ }^{32}$ However, a recent systematic review found insufficient evidence to conclude that alcohol server interventions were effective in preventing alcoholrelated injuries and in reducing customer consumption of alcoholic beverages. ${ }^{56}$

Ignition locks are another intervention used to decrease drinking and driving. These devices, which require the driver to provide a breath specimen prior to starting the ignition, are generally used with individuals who have had a prior drunk driving conviction and are intended to reduce recidivism. ${ }^{57}$ A Cochrane review of the relevant studies concluded that the use of these devices significantly reduced re-arrests for alcohol impaired driving (a median 70\% reduction); however, there is no evidence of long-term benefit once the device is removed. ${ }^{57}$

Alcohol warning labels have been implemented in the hopes of reducing alcohol consumption by highlighting the known consequences of use. In the US, warning labels have been required on alcohol containers since 1989 and focus on the risks associated with drinking and driving, operating machinery, and alcohol use during pregnancy. ${ }^{58}$ Studies indicate that the presence of warning labels on alcohol containers did increase awareness of the message, but have not had a significant impact on actual drinking behaviors. ${ }^{58}$

\section{Prevention programs}

Over the last several decades, the focus of alcohol prevention initiatives has expanded from preventing clinical alcoholism to preventing alcohol-related consequences. ${ }^{59} \mathrm{~A}$ public health perspective suggests a three pronged approach to prevention programming and includes a focus on the agent (alcohol), the individual, and the environment, as well as the interactions among these concepts. Prevention programs are generally universal or selective in scope. Universal programs are directed at the entire population and are the most commonly used approach to address underage drinking. ${ }^{9}$ Selective interventions are directed toward groups assumed to be at increased risk, for example, college age students. ${ }^{59}$

While at one time alcoholism was believed to be an exclusively adult problem, it is now well established that adolescence and young adulthood are the critical times for the development of alcohol use and dependence. ${ }^{10}$ Identifying the age at which individuals begin using alcohol has implications for the development of prevention programs. It has been suggested that in order to have the greatest impact, programs should aim to intervene prior to first use or during the early years of use, as there appears to be a transition period of 1-3 years before regular use and dependence develops. ${ }^{9}$ Therefore, the majority of US alcohol prevention programs are geared for school age and young adolescent groups.

Early educational programs focused on the dissemination of information using a didactic, classroom approach. These programs often highlighted the dangers of alcohol and drug use and frightened students with vivid descriptions of the associated consequences. ${ }^{60}$ Evaluations of these programs indicated they produced a temporary impact on knowledge and attitudes; ${ }^{60}$ however, a frequently cited meta-analysis reported these programs consistently failed to demonstrate any long-term impact on actual use or intention. ${ }^{61}$

Contemporary educational programs have included social resistance approaches, which incorporate resistance skills training to aid students in handling peer pressure, as well as competence enhancement approaches which focus on decision-making and problem solving skills. ${ }^{60}$ In addition to these skills, the most effective programs incorporate an interactive approach and information aimed at correcting misperceptions of normative alcohol use. ${ }^{62,63}$ The National Institute on Alcohol Abuse and Alcoholism (NIAAA) supports this approach as well as utilizing peer leaders, age-appropriate 
content, and consistency in educating instructors as additional components of effective programming. ${ }^{64}$

\section{School-based interventions}

The Safe and Drug-Free Schools program is a federally funded US initiative designed to prevent the use of alcohol, tobacco, drugs, and the perpetration of violence in public schools. ${ }^{65}$ In order to receive funding, school districts must provide comprehensive education and prevention programming. School-based programs have the advantage of being able to target a large number of students at a time when they may be contemplating the initiation of alcohol or substance use. ${ }^{60}$

The most widely utilized school-based program in the US was Drug Abuse Resistance Education (DARE), a primary prevention program for 5 th or 6 th grade students. ${ }^{66}$ DARE used trained, uniformed officers in the classroom to teach the curriculum. ${ }^{60}$ The program contained multiple components including information regarding substances, skills for situations with social pressure, and discussion of media influences. After years of implementation, this program was found to have negligible effects on preventing drug and alcohol use. ${ }^{67}$ The program was believed to be ineffective because it targeted the wrong mediating processes, the instructional method was noninteractive, and the students ignored the message being delivered by an obvious, authority figure. ${ }^{60}$

A number of current studies have reported significant positive findings associated with school-based programming. Faggiano and associates utilized a social influences approach with over 7,000 students and reported decreased episodes of drunkedness (prevalence odds ratio $=0.80$; confidence interval $=0.67-0.97$ ) at 18 months postintervention. ${ }^{68}$ Additional findings suggested a decrease in the reporting of alcohol-related problems as well as a reduction in the progress toward frequent drinking for students in the intervention group. ${ }^{69}$ In a school-based program that included a teacher-delivered, personality-targeted intervention with high-risk adolescent students, the results indicated a $40 \%$ reduction in alcohol consumption, as well as a $55 \%$ reduction in binge drinking rates. ${ }^{70}$

In a national, multi-site analysis of school and community-based programs, 48 youth-focused programs were analyzed and five characteristics of effective programs were identified. ${ }^{71}$ Programs with a strong behavioral component, ones that utilized introspective learning, and incorporated building connections were all reported to be effective. Among results based execution programs, those that met for more than 3.3 hours per week, had a consistent focus or theoretical framework, and had adequate staff training were more effective in preventing alcohol and other drug use. Interestingly, the findings also indicated that participants who were currently using substances reported a greater decrease in their use as compared with occasional and nonusing participants. ${ }^{71}$ These findings were supported by a recent review that reported that the most effective programs were directed at individuals who were "at risk" or who were already involved in alcohol or substance use. ${ }^{72}$

While these programs have reported reductions in early initiation and progression of alcohol use in younger and older adolescents, studies of elementary school students have often reported decreases in aggressive behavior as opposed to reductions in subsequent alcohol use. ${ }^{63}$ Additionally, few studies have followed students into middle school when drinking behaviors generally begin and even fewer studies have investigated interventions with high school students, a group with particularly high-risk (ie, binge drinking) behaviors. ${ }^{63}$ The need for refinement of current programming and the ongoing development of novel approaches to the implementation of school-based programming continues, as the problems associated with high-risk alcohol use remain a significant public health concern. ${ }^{73}$

\section{College-based programming}

In 1998, NIAAA established the Task Force on College Drinking to determine effective prevention strategies and to oversee implementation of programming for college students. ${ }^{10}$ The task force issued a report that categorized available prevention strategies into four levels based on the strength of the evidence and whether that evidence was specific to the college student populations. ${ }^{74}$ Tier 1 programs have evidence to support their effectiveness in college students and include motivation-based programs, norm setting, and cognitive behavioral approaches. ${ }^{75}$ Tier 2 strategies have been effective in other populations and may be effective in college students. ${ }^{74}$ These interventions include increasing the cost of alcohol, limitations on density of alcohol retailers, and increased enforcement of existing legislation such as zero tolerance laws. ${ }^{75}$ Tier 3 strategies appear promising and may be effective, but need more thorough investigation. ${ }^{74}$ These programs include campus policies to reduce drinking including free rides for those who have been drinking and media campaigns to correct misperceptions related to alcohol use. ${ }^{75}$ Finally, tier 4 strategies are those that have been shown to be ineffective including freshman orientation programming and alcohol awareness week programs. ${ }^{75}$ 
Nelson and colleagues conducted a nationally representative survey of college administrators to ascertain their progress toward implementation of the NIAAA recommendations to reduce college drinking. ${ }^{74}$ The results indicated that $98 \%$ of schools used educational programming to address student drinking and $50 \%$ offered intervention programs to students at high risk for alcohol problems. ${ }^{74}$ However, far fewer schools had implemented community-based strategies that include monitoring illegal alcohol sales (33\%), instituting responsible beverage service programs (15\%), restricting alcohol outlet density (7\%), and increasing the price of alcohol within their communities (2\%). ${ }^{74}$ Increasing numbers of researchers have called for colleges and communities to jointly create interventions as environmental approaches need to be integrated with college programming to increase program effectiveness. ${ }^{76}$

A recent review of college-based programs reported that individual interventions were one of the most effective programming strategies available. ${ }^{76}$ Specifically, brief motivational techniques, decision evaluation training, and norm assessments were reported to be most effective. ${ }^{76}$ Larimer and Cronce reported similar findings and suggested motivation based and cognitive behavioral skills interventions were effective in addressing alcohol use in college students. ${ }^{77}$ Additionally, they reported that face-to-face interventions were not required, as mail- and web-based interventions had shown promise. ${ }^{77} \mathrm{~A}$ recent meta-analysis confirmed that individual prevention interventions with normative feedback and motivational components were most successful. ${ }^{78}$

While statistically significant reductions in alcohol consumption have been reported in college age populations following brief screening and intervention programs, the results indicate relatively small effect sizes, as students in the intervention groups may be drinking less but are still drinking at substantial levels. ${ }^{79,80}$ It has been suggested that these findings may be related to the invincibility most adolescents and college age students feel as well as their limited contact with the most serious consequences of excessive alcohol use. ${ }^{79}$ While actual reductions in alcohol use may be small, they are consistent, and the use of these interventions has been endorsed by the NIAAA as tier 1 programs. ${ }^{81}$

In addition to these programs, a number of policy initiatives have been implemented on college campuses to reduce drinking behavior including the establishment of alcohol-free dormitories, prohibiting beer kegs and self-service of alcohol at campus events as well as banning alcohol advertising on campus. The impact of these initiatives has not been frequently studied; however, lower rates of binge drinking have been reported in alcohol free housing. ${ }^{82}$

\section{Family-based interventions}

Family-based primary prevention programs for at risk children have been proven to be efficacious for a wide range of social and health concerns. ${ }^{83}$ Family focused interventions addressing alcohol prevention have been primarily used with young children and adolescents. These programs typically focus on a range of behaviors that originate in family settings including child monitoring, parent-child bonding, effective discipline, and parental involvement in the child's activities. $^{63}$

Programs that were developed for families with preschool and younger age children have primarily demonstrated reductions in aggressive behavior, an identified risk factor for later alcohol use. ${ }^{63}$ Far fewer family-based prevention initiatives have been developed for school-aged children. Some of these programs have included both a school and family-based component. Programs addressing the needs of school age children have been reported to be effective in decreasing the initiation of alcohol use and subsequent use in the teenage years. ${ }^{63}$ Additional research on family-based interventions suggests that this approach is effective as results indicate that substance use is delayed and reduced in intervention groups as compared to controls. ${ }^{84,85}$ At the college level, parental relationships have been reported to influence college students' alcohol use. ${ }^{76}$ Family-based interventions may hold promise for future alcohol prevention efforts.

\section{Workplace-based interventions}

Few studies have addressed the workplace as a focus for alcohol use intervention programming. However, given that most adults spend a large portion of their time at work, this setting could be an optimal avenue by which to provide prevention education. ${ }^{86} \mathrm{~A}$ review of worker substance use and workplace policies reported that $8.8 \%$ or 10.1 million full time employees are heavy drinkers. ${ }^{87}$ Therefore, there is a clear need for employment-based programming to address this potentially underserved population.

Studies of alcohol education programs conducted in the work site are often associated with health promotion programs or Employee Assistance Programs (EAPs). Early studies indicated significant changes in alcohol attitudes following enrollment in these programs; $; 8,89$ however, follow-up evaluations did not reveal sustained change. ${ }^{89}$ Subsequent studies have demonstrated improved outcomes as evidenced by reduced alcohol consumption, fewer occurrences of 
alcohol-related negative work performance, and increased motivation to reduce alcohol use. ${ }^{90-93}$

It has been suggested that alcohol use could be addressed in the workplace through Employee Assistance Programs (EAPs), which have generally focused on secondary prevention by self-identification, informal or formal referral to these programs ${ }^{86}$ Another area in which to expand research is relapse prevention. An early study indicated that EAPs reduced the relapse rates of those enrolled compared to those without a relapse support program. ${ }^{94}$

\section{Community-based interventions}

Community-based interventions use a variety of prevention strategies that generally include a combination of educational initiatives and environmental changes. ${ }^{95}$ These programs primarily focus on changing the environment in which the person consumes alcohol and often target the individual drinker, vendors of alcohol, social events where alcohol is sold, local regulations and enforcement agencies, local medical facilities and personnel, as well as schools, churches, and business organizations that support public health campaigns. A number of community-based programs have been tried over the last 20 years with significant and positive outcomes.

The Saving Lives Project was conducted in six Massachusetts communities and targeted a reduction in alcohol impaired driving and related negative outcomes. The specific local community programs include a variety of activities such as media campaigns, business information programs, speeding and drunk driving awareness days, police training, high school student peer-led educational programs, as well as college prevention programs and the development of new Students Against Drunk Driving (SADD) chapters. ${ }^{96}$ The results indicate that during the 5 years of the program there was a $33 \%$ reduction in fatal car crashes and that this decline was $42 \%$ greater than that observed in the rest of the state. ${ }^{96}$

Holder and associates reported on a longitudinal multiple time series of matched interventions in California and South Carolina. ${ }^{97}$ The intervention included mobilizing community action, encouraging responsible beverage service, reducing underage drinking by limiting access to alcohol, and increased local enforcement of drinking and driving regulations. The results indicated significant reductions in the amount of alcohol consumed, in the number of individuals having had "too much to drink", and driving after drinking. Traffic and emergency room data revealed a decline in nighttime injuries due to car crashes as well as a reduction in assault injuries. ${ }^{97}$
The Communities Mobilizing for Change on Alcohol (CMCA) program was conducted in 15 communities in Minnesota and Wisconsin to reduce access to alcohol by underage youths. ${ }^{98}$ The program addressed community policies and practices, access to alcohol by underage persons, underage alcohol consumption and alcohol-related problems in underage drinkers. The results indicated that there were fewer sales of alcohol to minors, increased checking for proof of legal age to purchase alcohol, as well as a decline in drinking and driving arrests among 18-20 year olds. ${ }^{98}$

A recent systematic review of community-based programs targeting reductions in alcohol impaired driving as well as other alcohol-related negative consequences reported that well executed, multi-component interventions were effective in reducing alcohol-related crashes. ${ }^{99}$ The community programs studied included responsible beverage service, efforts to limit alcohol access, sobriety checkpoints, and a media component. Based on the results of these findings, the Task Force on Community Preventative Services, an independent, nonfederal body of nationally known leaders in public health practice, policy, and research appointed by the US Centers for Disease Control and Prevention (CDC) director, recommended that multi-component community interventions be widely implemented. ${ }^{100}$

The United States Preventative Services Task Force (USPSTF) recommends screening for alcohol misuse as a method of secondary prevention in medical settings. ${ }^{101}$ Screening, brief intervention, and referral to treatment (SBIRT) programs have reported consistent effectiveness in both primary care and emergency department (ED) settings. ${ }^{102-104}$ These programs are based on the components of motivational interviewing and incorporate feedback on the individual's alcohol use and any alcohol-related harms; information on the consequences associated with high-risk alcohol use; benefits of reducing alcohol consumption, motivational enhancement, and development of a personal plan to reduce consumption. ${ }^{104}$

A recent multi-site study of a SBIRT program with emergency department clients reported a reduction of three drinks per week as well as a decrease in the maximum number of drinks consumed by participants who completed the intervention, thereby supporting the short-term effectiveness of these techniques. ${ }^{102}$ These techniques have also been studied in primary care settings. In a systematic review, which included 5800 participants, alcohol consumption was significantly reduced for those in the intervention group, as compared to controls, at - year postintervention. ${ }^{104}$ Based on the large volume of evidence supporting the use of these techniques, 
the WHO, USPSTF, as well as the Committee on Trauma of the American College of Surgeons, have endorsed routine alcohol screening and brief interventions in primary care and Level I trauma centers. ${ }^{23}$ While the implementation of these interventions across all possible venues may require an increase in the outlay of resources, these procedures are currently reimbursable under Medicare and Medicaid programs. $^{23}$

\section{Conclusion}

Problematic alcohol consumption remains a significant health concern in the United States as evidenced by rates of underage alcohol use, current drinking patterns of adolescents and college age students, as well as the rates of alcohol-related negative consequences. The statistics can be staggering; however, as indicated in this review, a number of prevention initiatives have been successful in reducing both rates of consumption and the associated negative health outcomes. Public health officials need to continue their vigilance in developing comprehensive and innovative programming to prevent excessive alcohol use and its potentially devastating consequences.

\section{Acknowledgment}

Work on this article was supported by the National Institute for Nursing Research Grant (NINR) 1K23NR011175.

\section{Disclosure}

No conflicts of interest were declared in relation to this paper.

\section{References}

1. Schoenborn CA, Adams PF. Health behavior of adults: US, 2005-2007. Vital Health Stat. 2010; Series 10(245):7-18.

2. Falk D, Yi H-Y, Hiller-Sturmhofel S. An epidemiologic analysis of cooccurring alcohol and drug use and disorders: findings from the National Epidemiologic Survey of Alcohol and Related Conditions. Alcohol Res Health. 2008;31(2):100-110.

3. Fryar CD, Merino MC, Hirsch R, Porter KS. Smoking, alcohol use and illicit drug use by adolescents aged 12-17 years United States, 1999-2004. Natl Health Stat Report. 2009;15:1-23.

4. Wechsler H, Lee JE, Kuo M, Seibring M, Nelson TF, Lee H. Trends in college binge drinking during a period of increased prevention efforts. Findings from 4 Harvard School of Public Health College Alcohol Study surveys: 1993-2001. J Am Coll Health. 2002;50(5):203-217.

5. Centers for Disease Control and Prevention. Frequently asked questions. Available at: http://www.cdc.gov/alcohol/faqs.htm. Accessed April 3, 2011.

6. Grant BF, Dawson DA, Stinson FS, et al. The 12 month prevalence and trends in DSM-IV alcohol abuse and dependence: United States, 1991-1992 and 2001-2002. Drug Alcohol Depend. 2004;74(3): 223-234.

7. Windle M, Scheidt DM. Alcohol subtypes: are two sufficient? Addiction. 2004;99(12):1508-1519.
8. Johnston ID, O’Malley PM, Bachman JG, Schulenberg JE. Monitoring the future national survey results on drug use, 1975-2008: Volume I, secondary school students. Bethesda, MD: National Institute on Drug Abuse; 2009.

9. Wittchen HU, Behrendt S, Hofler M, et al. What are the high risk periods for incident substance use and transitions to abuse and dependence? Implications for early intervention and prevention. Int J Methods Psychiatr Res. 2008;17(S1):S16-S29.

10. Windle M, Zucker RA. Reducing underage and young adult drinking: how to address this developmental period. Alcohol Res Health. 2010; 33(1):29-44.

11. Witt E. Research on alcohol and adolescent brain development: opportunities and future directions. Alcohol. 2010;44(1):119-124.

12. Monti PM, Robert M, Nixon K, et al. Adolescence: booze, brains, and behavior. Alcohol Clin Exp Res. 2005;29(2):207-220.

13. Crego A, Rodriguez-Holguin S, Parada M, et al. Reduced anterior prefrontal cortex activation in young binge drinkers during a visual working memory task. Drug Alcohol Depend. 2010;109(1-3):45-56.

14. DeBellis M, Clark D, Beers SR, et al. Hippocampal volume in adolescentonset alcohol use disorders. Am J Psychiatry. 2000;157(5):737-744.

15. Medina KL, Schweinsburg AD, Cohen-Zion M, Tapert SF. Effects of alcohol and combined marijuana and alcohol use during adolescence on hippocampal volume and asymmetry. Neurotoxicol Teratol. 2007;29(1):141-152.

16. Nagel BJ, Schweinsburg AD, Phan V, Tapert SF. Reduced hippocampal volume among adolescents with alcohol use disorders without psychiatric comorbidity. Psychiatr Res. 2005;139(3):181-190.

17. Room R, Babor T, Rehm J. Alcohol and public health. Lancet. 2005;365(9458):519-530.

18. van Gils PF, Hamberg-van Reenen H, van den Berg M, Tariq L, de Wit GA. The scope of costs in alcohol studies: cost-of-illness studies differ from economic evaluations. Cost Eff Resour Alloc. 2010;8:15.

19. Centers for Disease Control. Alcohol-attributable deaths and years of potential life lost-United States, 2001. MMWR. September 24, 2004;53(37):866-870.

20. World Health Organization [WHO]. Evidence-based strategies and interventions to reduce alcohol-related harm. Geneva, Switzerland: WHO; 2007; A60/14.

21. Hingson RW, Zha W, Weitzman ER. Magnitude of and trends in alcohol-related mortality and morbidity among US college students ages 18-24, 1998-2005. J Stud Alcohol Drugs Supp. 2009;16:12-20.

22. World Health Organization [WHO]. Towards a global strategy to reduce harmful use of alcohol. Geneva, Switzerland: WHO; 2009.

23. Madras BK, Compton WM, Avula D, et al. Screening, brief interventions, referral to treatment (SBIRT) for illicit drug and alcohol use at multiple healthcare sites: comparison at intake and 6 months later. Drug Alcohol Depend. 2009;99(1-3):280-295.

24. Tracy SW. Alcoholism in America from reconstruction to prohibition. Baltimore, MD: John Hopkins University Press; 2005.

25. Mintz S. Digital history. Available at: http://www.digitalhistory.uh.edu. Accessed April 3, 2011.

26. Hall $\mathrm{W}$. What are the policy lessons of national alcohol prohibition in the United States, 1920-1933? Addiction. 2010;105(7):1164-1173.

27. American Medical Association. Minimum legal drinking age. Available at: http://www.ama-assn.org/ama/pub/physician-resources/public health. Accessed April 3, 2011.

28. Komro KA, Toomey TL. Strategies to prevent underage drinking. National Institute on Alcohol Abuse and Alcoholism. Available at: http://www.ama-assn.org/ama/pub/physician-resources/publichealth. Accessed April 3, 2011.

29. Miron JA, Tetelbaum E. Does the minimum legal drinking age save lives? Working paper 13257. National Bureau of Economic Research; 2007 July; Cambridge, MA. Available at: http://www.nber.org/papers/ w13257. Accessed April 3, 2011.

30. McCartt AT, Hellinga LA, Kirley BB. The effects of minimum legal drinking age 21 laws on alcohol-related driving in the United States. J Safety Res. 2010;41(2):173-181. 
31. Norberg KE, Bierut LJ, Grucza RA. Long term effects of minimum drinking age laws on past year alcohol and drug use disorders. Alcohol Clin Exp Res. 2009;33(12):2180-2190.

32. Shults RA, Elder RW, Sleet DA, et al. Reviews of evidence regarding interventions to reduce alcohol impaired driving. Am J Prev Med. 2001;21(S4):66-88.

33. Traffic Safety Facts. 08 BAC illegal per se level. March 2004;2(1). Available at: www.nhtsa.dot.gov. Accessed April 3, 2011.

34. Buddy T. Blood alcohol content. Available at: http://alcoholism.about. com/cs/basics/g/bac.htm. Accessed April 3, 2011.

35. Hingson R, Heeren T, Winter M. Lowering state legal blood alcohol limits to $0.08 \%$ : the effect on fatal motor vehicle crashes. AJPH. 1996; 86(9): 1297-1299.

36. Fell JC, Voas RB. The effectiveness if reducing illegal blood alcohol concentration (BAC) limits for driving: evidence for lowering the limit to 0.05 BAC. J Safety Res. 2006;37(3):233-243.

37. National Highway Safety [NHTSA]. The facts: zero tolerance. Washington, DC. Available at: http://www.nhtsa.gov/people/outreach/ safesobr/13qp/facts/factzero.html. Accessed April 4, 2011.

38. Hingson R, Heeren T, Winter M. Lower legal blood alcohol limits for young drivers. Public Health Reports. 1994;109(6):738-744.

39. Martin SE, Voas R, Hingson R. Zero tolerance laws: effective public policy? Alcohol Clin Exp Res. 1996;20(Suppl 8):147A-150A.

40. Fell JC, Fisher DA, Voas RB, Blackman K, Tippetts AS. The impact of underage drinking laws on alcohol-related fatal crashed of young drivers. Alcohol Clin Exp Res. 2009;33(7):1208-1219.

41. Voas RB, Tippetts AS, Fell JC. Assessing the effectiveness in minimum legal drinking age and zero tolerance laws in the United States. Accid Anal Prev. 2003;35(4):579-587.

42. Kuunders M. Alcohol policies. Evidence: effective policy measures. Available at: http://www.euphix.org/object_document/o5222n29045. html. Accessed April 3, 2011.

43. Anderson P, Chisholm D, Fuhr DC. Effectiveness and cost-effectiveness of policies and programmes to reduce the harm caused by alcohol. Lancet. 2009;373(9682):2234-2246.

44. Coate D, Grossman M. The effects of alcoholic beverage prices and legal drinking ages in youth alcohol use. J Law Econ. 1988;31(1):145-171.

45. Saffer H, Grossman M. Beer taxes, the legal drinking age, and youth motor vehicle fatalities. J Legal Studies. 1987;16(2):351-374.

46. Wagenaar AC, Salois MJ, Komro KA. Effects of beverage alcohol price and tax levels on drinking: a meta-analysis of 1003 estimates from 112 studies. Addiction. 2009;104(2):191-192.

47. Middleton JC, Hahn RA, Kuzara JL, et al. Effectiveness of policies maintaining or restricting days of alcohol sales on excessive alcohol consumptions and related harms. Am J Prev Med. 2010;39(6):575-589.

48. Duailibi S, Ponicki W, Grube J, Pinsky I, Laranjeira R, Raw M. The effect of restricting opening hours on alcohol-related violence. AJPH. 2007;97(12):2276-2280.

49. Campbell CA, Hahn RA, Elder R, et al. The effectiveness of limiting alcohol outlet density as a means of reducing excessive alcohol consumption and alcohol related harms. Am J Prev Med. 2009;37(6):556-569.

50. Britt HR, Carlin BP, Toomey T, Wagenaar AC. Neighborhood level spatial analysis of the relationship between alcohol outlet density and criminal activity. Environ Ecol Stat. 2005;12(4):411-426.

51. Chen MJ, Gruenewald PJ, Remer LG. Does alcohol outlet density affect youth access to alcohol? J Adolesc Health. 2009;44(6):582-589.

52. Livingston M, Chikritzhs T, Room R. Changing the density of alcohol outlets to reduce alcohol related problems. Drug Alcohol Rev. 2007;26(5):557-566.

53. Chen MJ, Grube JW, Gruenewald PJ. Community alcohol outlet density and underage drinking. Addiction. 2010;105(2):270-278.

54. Shults RA, Kresnow M, Lee KC. Driver- and passenger-based estimates of alcohol-impaired driving in the US, 2001-2003. Am J Prev Med. 2009;36(6):515-522

55. Elder RW, Shults RA, Sleet DA, Nichols JL, Zaza S, Thompson RS. Effectiveness of sobriety checkpoints for reducing alcohol-involved crashes. Traffic Inj Prev. 2002;3(4):266-274.
56. Ker K, Chinnock P. Interventions in the alcohol server setting for preventing injuries. Cochrane Database Syst Rev. 2008;3:CD005244.

57. Willis C, Lybrand S, Bellamy N. Alcohol ignition interlock programmes for reducing drink driving recidivism. Cochrane Database Syst Rev. 2004;4:CD004168.

58. Wilkinson C, Room R. Warnings on alcohol containers and advertisements: international experience and evidence on effects. Drug Alcohol Rev. 2009;28(4):426-435.

59. Committee to Identify Research Opportunities in the Prevention and Treatment of Alcohol related Problems, Institute of Medicine [IOM]. Preventions and treatment of alcohol problems: research opportunities. Washington, DC: National Academies Press; 1990.

60. Botvin G, Griffin KW. Drug and alcohol abuse: school. Available at: http://education.stateuniversity.com/pages/1923/Drug-Alcohol-Abuse Accessed April 3, 2011.

61. Tobler NS, Stratton HH. Effectiveness of school based drug prevention programs: a meta-analysis of the research. J Prim Prev. 1997;18(1):71-128.

62. Botvin GJ, Griffin KW. School based programmes to prevent alcohol, tobacco and other drug use. Int Rev Psychiatry. 2007;19(6):607-615.

63. Spoth R, Greenberg M, Turrisi R. Overview of preventative interventions addressing underage drinking: state of the evidence and steps toward public health impact. Alcohol Res Health. 2009;32(1):53-66.

64. National Institute on Alcohol Abuse and Alcoholism [NIAAA]. Interventions for alcohol use and alcohol use disorders in youth. Alcohol Res Health. 2004-2005;28(3):163-174.

65. US Department of Education. Safe and drug free schools. Available at: http://www2.ed.gov/about/offices/list/osdfs/index.html. Accessed April 3, 2011

66. Clayton RR, Cattarello AM, Johnstone BM. The effectiveness of drug abuse resistance education (project DARE): 5-year follow-up results. Prev Med. 1996;25(3):307-318.

67. Pan W, Bai H. A multi-variate approach to a meta-analytic review of the effectiveness of the D.A.R.E. program. Int J Environ Res Public Health. 2009;6(1):267-277.

68. Faggiano F, Vigna-Taglianti F, Burkhart G, et al. The effectiveness of a school based substance abuse prevention program: 18 month follow-up of the EU-Dap cluster randomization controlled trial. Drug Alcohol Depend. 2010;108(1-2):56-64.

69. Caria MP, Faggiano F, Bellocco R, Galanti MR; EU-Dap Study Group Collaborators. Effects of a school based prevention program on European adolescents' patterns of alcohol use. J Adolesc Health. 2011;48(2):182-188.

70. O’Leary-Barrett M, Mackie CJ, Castellanos-Ryan N, Al-Khudhairy N, Conrod PJ. Personality-targeted interventions delay uptake of drinking and decrease risk of alcohol related problems when delivered by teachers. J Am Acad Child Adolesc Psychiatry. 2010;49(9):954-963.

71. Sambrano S, Springer JF, Sale E, Kasim R, Hermann J. Understanding prevention effectiveness in real-world settings: the national cross-site evaluation of high risk youth programs. Am J Drug Alcohol Abuse. 2005;31(3):491-513.

72. Shamblen SR, Derzon JH. A preliminary study of the populationadjusted effectiveness of substance abuse prevention programming: towards making IOM program types comparable. J Prim Prev. 2009; 30(2):89-107.

73. Skager R. Replacing ineffective early alcohol/drug education in the United States with age appropriate adolescent programmes and assistance to problematic users. Drug Alcohol Rev. 2007;26(6):577-584.

74. Nelson TB, Toomey TL, Lenk KM, Erickson DJ, Winter KC. Implementation of NIAAA college drinking task force recommendations: how are colleges doing 6 years later? Alcohol Clin Exp Res. 2010; 34(10):1687-1698.

75. DeJong W, Larimer ME, Wood MD, Hartman R. NIAAA's rapid response to college drinking problems initiaitive: reinforcing the use of evidence-based approaches in college alcohol prevention. J Stud Alcohol Drugs. 2009;(Suppl 16):5-11.

76. Hingson RW. Magnitude and prevention of college drinking and related problems. Alcohol Res Health. 2010;33(1):45-54. 
77. Larimer ME, Cronce JM. Identification, prevention and treatment revisited: individual-focused college drinking prevention strategies 1999-2006. Addictive Behav. 2007:32(11):2439-2468.

78. Carey KB, Scott-Sheldon LAJ, Carey MP, DeMartini KS. Individuallevel interventions to reduce college drinking: a meta-analytic review. Addictive Behav. 2007;32(11):2569-2494.

79. Fleming MF, Balousek SL, Grossberg PM, et al. Brief physician advice for heavy drinking college students: a randomized controlled trial in college health clinics. J Stud Alcohol Drugs. 2010;71(1):23-31.

80. Schaus JF, Sole ML, McCoy TP, Mullett N. Alcohol screening and brief intervention in a college student health center: a randomized controlled trial. J Stud Alcohol Drugs. 2009;(Supp 16):131-141.

81. Fleming MF. Clinical protocols to reduce high risk drinking in college students: the college drinking prevention curriculum for health care professionals. Bethesda, MD: NIAAA; 2002.

82. Toomey TL, Wagenaar AC. Environmental policies to reduce college drinking: options and research findings. J Stud Alcohol. 2002;(Suppl 14): 193-205.

83. Alexander JF, Robbins MS, Sexton TL. Family based interventions with older at risk youth: from promise to proof to practice. J Prim Prev. 2000;21(2):185-201.

84. Spoth R, Redmond C, Shin C, Azevedo K. Brief family intervention effects on adolescent substance initiation: school-level growth curve analyses 6 years following baseline. J Consult Clin Psychol. 2004;72(3):535-542.

85. Spoth RL, Redmond C, Shin C. Randomized trial of brief family interventions for general populations: adolescent substance use outcomes 4 years following baseline. J Consult Clin Psychol. 2001; 69(4):627-642.

86. Roman PM, Blum TC. The workplace and alcohol problem prevention. Alcohol Res Health. 2002;26(1):49-57.

87. Larson SL, Eyerman J, Foster MS, Gfroerer JC. Worker substance use and workplace policies and programs. DHHS publication $\mathrm{nr}$ SMA 07-4273. Rockville, MD: Substance Abuse and Mental Health Services Administration; 2007. Available at: http://www.oas.samhsa. gov/work2k7/work.pdf. Accessed April 4, 2011.

88. McLatchie BH, Grey PM, Johns Y, Lomp GE. A component analysis of an alcohol and drug program: employee education. J Occup Environ Med. 1981;23(7):477-480.

89. Brochu S, Souliere M. Long term evaluation of a life skills approach for drug and alcohol prevention. J Drug Educ. 1988;18(4):311-331.

90. Cook RF, Back AS, Trudeau J. Substance abuse prevention in the workplace: recent findings and an expanded conceptual model. J Prim Prev. 1996;16(3):319-339.

91. Richmond R, Kehoe L, Heather N, Wodak A. Evaluation of a workplace brief intervention for excessive alcohol consumption: the workscreen project. Prev Med. 2000;30(1):51-63.
92. Bennett JB, Patterson CR, Reynolds GS, Wiitala WL, Lehman WE. Team awareness, problem drinking, and drinking climate: workplace social health promotion in a policy context. Am J Health Promot. 2004;19(2):103-113.

93. Ennenbach M, Gass B, Reinecker H, Soyka M. Efficiency of an alcohol addiction prevention program at the workplace: results of an empirical study [abstract]. Nervenarzt. 2009;80(3):305-314; German.

94. Foote A, Erfurt JC. Effects of EAP follow up on prevention of relapse among substance abuse clients. J Stud Alcohol. 1991;52(3): 241-248.

95. Allamani A, Casswell S, Graham K, et al. Introduction: community action research and the prevention of alcohol problems at the local level. Subst Use and Misuse. 2000;35(1-2):1-10.

96. Hingson R, McGovern T, Howland J, et al. Reducing alcohol impaired driving in Massachusetts: The Saving Lives Program. Am J Public Health. 1996;86(6):791-797.

97. Holder HD, Gruenewald PJ, Ponicki WR, et al. Effect of community based interventions on high risk drinking and alcohol related injuries. JAMA. 2000;284(18):2341-2347.

98. Wagenaar AC, Murray DM, Gehan JP, et al. Communities Mobilizing for Change on Alcohol (CMCA): outcomes from a randomized community trial. J Stud Alcohol. 2000;61(1):85-94.

99. Shults RA, Elder RW, Nichols J, et al. Effectiveness of multicomponent programs with community mobilization for reducing alcoholimpaired driving. Am J Prev Med. 2009;37(4):360-371.

100. Centers for Disease Control and Prevention. Meeting of the task force on community preventive services. The Federal Register. October 18, 2010. Available at: http://www.federalregister.gov/ articles/2010/10/18/2010-26133/meetings. Accessed April 3, 2011.

101. United States Preventative Services Task Force. Screening and behavioral counseling interventions in primary care to reduce alcohol misuse. Available at: http://www.uspreventiveservicestaskforce.org/ uspstf/uspsdrin.htm. Accessed April 4, 2011.

102. Academic ED SBIRT Research Collaborative. The impact of screening, brief intervention and referral for treatment in emergency department patients' alcohol use: a 3-, 6-, and 12-month follow-up. Alcohol Alcohol. 2010;45(6):514-519.

103. Bernstein E, Bernstein JA, Stein JB, Saitz R. SBIRT in emergency care settings: are we ready to take it to scale? Acad Emerg Med. 2009;16(11):1072-1077.

104. Kaner EFS, Dickinson HO, Beyer F, et al. The effectiveness if brief alcohol interventions in primary care settings: a systematic review. Drug Alcohol Rev. 2009;28(3):301-323.
Patient Intelligence

\section{Publish your work in this journal}

Patient Intelligence is an international, peer-reviewed, open access journal that characterizes and measures the central role of patient behavior and intention in optimizing healthcare management in all areas of disease and complaint types. An improved understanding of patient intelligence coupled with predictive analysis helps an organization contribute more effectively to achieving better outcomes.

Submit your manuscript here: http://www.dovepress.com/patient-intelligence-journal

\section{Dovepress}

The journal is characterized by the rapid reporting of reviews, original research, methodologies, analytics, modeling, clinical studies and patient surveys across all disease areas. The manuscript management system is completely online and includes a very quick and fair peer-review system. Visit http://www.dovepress.com/ testimonials.php to read real quotes from published authors. 